\title{
Preadolescents' Perceptions of Females' Body Size and Shape: Evolutionary and Social Learning Perspectives
}

\author{
Charlotte N. Markey, ${ }^{1}$ Barbara J. Tinsley, ${ }^{2}$ Andrea J. Ericksen, ${ }^{3}$ \\ Daniel J. Ozer, ${ }^{4}$ and Patrick M. Markey ${ }^{5}$
}

Received December 10, 2000; accepted October 4, 2001

One hundred and sixty-five Mexican American and Euro-American preadolescents' and their parents' perceptions of healthy and attractive female body sizes and shapes were examined in this study. Participants' perceptions of healthy and attractive female figures were assessed using a pictorial measure that systematically manipulated 3 levels of body size and 4 levels of body shape (i.e., waistto-hip ratio; WHR). All participants tended to perceive females' with small WHRs as most healthy and attractive looking, while preadolescents expressed a preference for thinner female figures than did adults. Results further suggest that Euro-American and Mexican American participants report similar preferences for females' body sizes and shapes. However, little agreement was found between preadolescents' and their parents' preferences. Principles of evolutionary theory and social learning theory are used to interpret these findings, and implications for preadolescents' perceptions of their own developing bodies, body image, and related eating behaviors are discussed.

KEY WORDS: waist-to-hip ratio; body size; body image; preadolescents.

\section{INTRODUCTION}

For decades, social psychologists and laypersons alike have sought to uncover the nature of interpersonal

\footnotetext{
${ }^{1}$ Doctoral candidate, Department of Psychology, University of California, Riverside, California. Research interests include examination of sociocultural influences on eating-related behaviors and the relations between personality and health. To whom correspondence should be addressed at Healthy Families Project, Department of Psychology, University of California, Riverside, California 92521; e-mail: ccastro@ citrus.ucr.edu.

${ }^{2}$ Professor, Department of Psychology, University of California, Riverside, California. Received PhD in 1984, in Human Development and Educational Psychology from University of Illinois. Major research interests are the development of children's health understanding and behavior within family and cultural contexts.

${ }^{3}$ Doctoral candidate, Department of Psychology, University of California, Riverside, California. Major research interests are sociocultural influences on preadolescents' health beliefs and behaviors.

${ }^{4}$ Associate Professor, University of California, Riverside, California. Received Psychology PhD from UC Berkeley. Research interests are in the area of personality assessment and quantitative methods.

${ }^{5}$ Doctoral candidate, University of California, Riverside, California. Research interests include examining the links between motivation and social behavior.
}

attraction. A primary focus of these quandries has been the investigation of the determinants of perceptions of physical attractiveness. While previously concentrating on facial appearances (Dion, 1973; Langlois and Roggman, 1990; Langlois et al., 1994), recent endeavors aimed at understanding perceptions of attractiveness have examined bodily appearances, particularly with respect to women's appearance (Ericksen et al., 2000; Rosenblum and Lewis, 1999; Singh and Luis, 1995). ${ }^{6}$ Two theoretical perspectives have been incorporated into the discussion of perceptions of bodily attractiveness: social learning theory (Klesges et al., 1986; Pike and Rodin, 1991) and evolutionary theory (Singh, 1993). These different theories have been used to explain perceptions of two dimensions of bodily appearance: body size and body shape. The present study represents an initial attempt to draw from both of these theoretical approaches in order to gain a

\footnotetext{
${ }^{6}$ The present study will focus on perceptions of females' body size and shape because of research suggesting that cultural standards of appropriate body size and shape are more restricted for females, females express greater concerns about their bodily appearance, and perceptions of body size and shape are more integral to female's self-concept (Harter, 1998; Pliner et al., 1990).
} 
greater understanding of preadolescents' perceptions of bodily appearances.

Adults (e.g., college students) are typically the focus of psychologists' attempts to understand perceptions of attractiveness. However, developmental research suggests that concerns about perceptions of physical appearances may be most salient during the beginning of second decade of life when the vast physiological changes experienced during puberty promote the body as a focus of concern (Attie and Brooks-Gunn, 1989; 1995; Brooks-Gunn and Reiter, 1990; Slap et al., 1994). Research addressing the development of body image further indicates that adolescents experience greater concerns about their physical appearance, in particular their developing bodies, than do children or adults (Altabe and Thompson, 1993). Adolescents' satisfaction with their bodies contributes to positive mental and physical health as well as increased satisfaction in a variety of interpersonal domains (Harter, 1990, 1998; Rosenblum and Lewis, 1999). Thus, an evaluation of preadolescents' perceptions of females' body size and shape can add insight into the development of these perceptions, and has implications for adolescents' identity development.

\section{Sociocultural Explanations of Preferences for Females' Body Size}

Preferences for specific female body sizes are believed to be learned in social and cultural contexts. Research suggests that children learn what is considered attractive with regard to facial beauty (Dion, 1973) and body size (Davison et al., 2000; Goldfield and Chrisler, 1995; Lerner and Gellert, 1969) within their social and cultural context at a very young age. In the United States researchers consistently find an overwhelming preference among adults and children for thin female figures (Cramer and Steimwert, 1998; Feldman et al., 1988; Gordon, 2000; Powers and Erickson, 1986). For example, Collins (1991) found that female preadolescents select pictures to represent "ideal" body figures that are significantly thinner than themselves, and body dissatisfaction is discussed as normative among female adolescents (Attie and BrooksGunn, 1995; Feldman et al., 1988; Maloney et al., 1989; Rolland et al., 1996, 1997). Further, recent research has documented a preference for thinness among children of increasingly younger ages, with a recent study even suggesting that 5-year-old girls are aware of perceptions of bodily attractiveness, and express a desire to be thin (Davison et al., 2000).

Parental influences, both direct (e.g., explicit dialogue; Klesges et al., 1986) and indirect (e.g., modeling; Pike and Rodin, 1991; Stice, 1998), have been implicated in children's development of ideas concerning what constitutes an "ideal" female figure. Prior research further suggests that peers influence children's understanding of "appropriate" figures, and as early as preschool, children exhibit aversions to overweight individuals (Goldfield and Chrisler, 1995; Lerner and Gellert, 1969). The media, which reflects and promotes cultural beliefs and values, is also believed to influence youths' preferences for thin female figures by exhibiting myriad underweight female models (Field et al., 1999; Wiseman et al., 1992).

While thin figures are typically regarded as ideal in mainstream, Euro-American culture, cross-ethnic research reveals differing perceptions of attractive and healthy body sizes according to ethnic group (Powers, 1980). This has led to speculation that cultural processes and value systems contribute to the development of standards that influence individuals' perceptions of body sizes. For example, outside the United States, differing preferences regarding female body size have been found, with residents of less "Westernized," developing countries preferring large women (Brown and Konner, 1987). Body fat is believed to be an indicator of wealth and prosperity in some societies that are lacking in the availability of resources to provide adequate nutrition (e.g., Western Samoa; Martin, 1989), with obesity a symbol of economic success, femininity, and sexual capacity (Powers, 1980; Rudofsky, 1972).

Within the United States, different ethnic groups (e.g., African Americans, Mexican Americans) report preferences for women larger in size than the thin figures preferred by the majority, Euro-American population (Jackson and McGill, 1996; Thompson et al., 1997; Winkelby et al., 1996). For example, Hispanic ${ }^{7}$ men and women report higher desired body weights than those reported by Euro-American men and women, and EuroAmericans report a desire to lose more weight than do Hispanics (Winkelby et al., 1996). In sum, research consistently suggests that individuals' social-ecological context plays a significant role in the development of perceptions concerning appropriate and desirable size figures (Goldfield and Chrisler, 1995; Pike and Rodin, 1991; Stice, 1998; Thompson et al., 1997).

\section{An Evolutionary Explanation of Preferences for Females' Body Shape}

While psychologists suggest that social learning contributes to perceptions of body size, recently researchers have speculated that evolutionary theory can help us understand preferences for female body shapes (Singh,

\footnotetext{
${ }^{7}$ Throughout this manuscript, we have preserved the referent used by the original authors when possible.
} 
1993; 1994a,b,c; Singh and Luis, 1995). Thus, while the majority of research on body perceptions focuses on learned preferences for particular body sizes, Singh (1993; 1994a,b,c; Singh and Luis, 1995) asserts a universal, evolutionarily adaptive, preference for curvaceous female body shapes.

To assess preferences for body shapes, Singh (1993; 1994a,c) has developed and used a pictorial measure that simultaneously manipulates female body size and shape, and is therefore capable of independently assessing the contributions of shape and size to individuals' perceptions of female figures. This measure consists of drawings portraying females with varying weight (size) groups ("thin," "normal," and "overweight") combined with varying waist-to-hip ratio (shape) groups $(0.7,0.8,0.9,1.0$; see Fig. 1). Waist-to-hip ratio (WHR) is a ratio determined by measurements of the waist at its smallest point divided by measurements of the hips at their widest point. Thus, WHR is an indicator of body shape, with a high (1.0) WHR signifying a waist and hips of approximately the

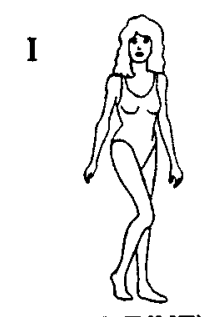

WHR $\quad \mathbf{0 . 7 ( U 7 )}$

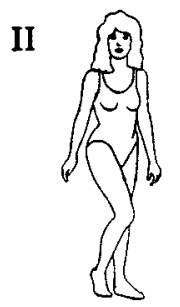

WHR 0.7 (N7)

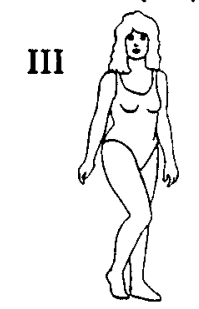

WHR $0.7(07)$

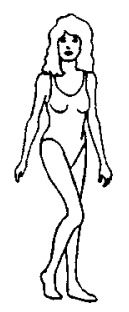

0.8 (U8)

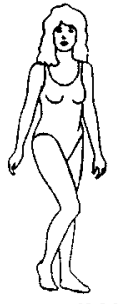

0.8 (N8)

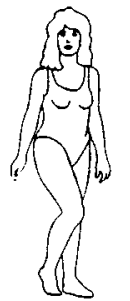

$0.8(08)$

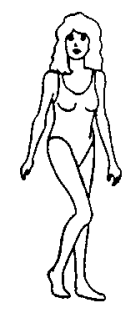

0.9 (U9)

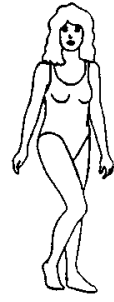

0.9 (N9)
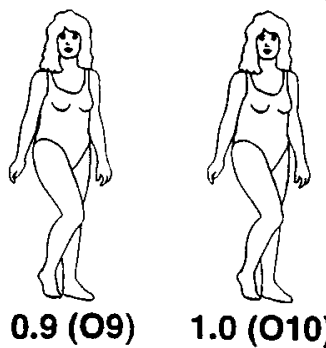

$1.0(010)$
Fig. 1. Female stimulus figures representing three body weight categories (rows) and four waist-to-hip ratios (columns). Reprinted with permission from Singh (1993) () Journal of Personality and Social Psychology. (Note. Parents viewed all 12 stimuli presented above. Children saw 6 of the 12 stimuli, namely, all of the figures in row 2 and all of the figures in column 1.) same size, and a small WHR (0.7) signifying a waist that is substantially smaller than the hips resulting in a shapely, hourglass figure.

Research by Singh has demonstrated the importance of WHR in understanding the influence that body shape has on adults' perceptions of both attractiveness and healthiness (Singh, 1993; 1994a,b,c; Singh and Luis, 1995). Among adults residing in the United States, pictures portraying women with "normal" weights and small WHRs are perceived as most attractive to both men and women (Singh, 1993; 1994a; Singh and Luis, 1995). Singh (1993) found that men ranging in age from 25 to 85 years consistently perceived pictures of women with low WHRs as more attractive, healthier, and of greater reproductive potential, than pictures of figures with high WHRs. Furthermore, in studies evaluating U.S. college-age African American, Indonesian, and Caucasian men's and women's perceptions of desirable female body shapes, both male and female participants identified pictures of female figures maintaining a "normal" weight and a low WHR as most attractive (Singh, 1993; Singh and Luis, 1995).

Adults' preference, regardless of gender, age, or ethnicity, for women's figures with small WHRs has led researchers to speculate about the origin of this bias. Singh (1993) evokes an evolutionary explanation to account for this preference, stressing that women with small WHRs enjoy better health and reproductive capacity (Singh, 1993). Empirical research has substantiated the role of fat distribution in determining individuals' overall health status (Bjorntorp, 1988; 1991), with women maintaining small WHRs exhibiting better health outcomes on a number of dimensions, relative to women who have larger WHRs. Specifically, women who have greater fat deposits in their abdominal regions (and therefore higher WHRs) are at greater risk for diabetes, heart disease, and stroke (Jones et al., 1986). Thus, according to this evolutionary perspective, preferences for small WHRs are not only due to men's aesthetic inclinations, but reflect adaptive selection for mating.

\section{Aims of the Present Study}

This study contributes to the current literature examining individuals' preferences for females' figures of particular sizes and shapes by evaluating these attitudes among preadolescents, and by evaluating evolutionary and social learning explanations for preadolescents' preferences for females' figures. In support of social learning explanations for the development of preferences for females' body size, it is anticipated that parents' preferences for females' body size will resemble their preadolescent children's preferences. Additionally, the data is expected 
to reflect individuals' learning of preferences for females' body size within their cultural group by indicating a difference between Mexican Americans' and Euro-Americans' perceptions of females' body size. An evolutionary explanation for preferences for female body shape will be supported if all participants express a unanimous preference for small WHRs.

\section{METHOD}

\section{Participants}

The participants were 165 Mexican American and Euro-American 4th grade students and their parent(s). The participating children were 90 boys (54\%) and 75 girls (46\%) ranging in age from 9 to 11 years old $(M=10.0)$. Ninety-one (91) of the families participating were EuroAmerican (56\%), and 74 of the families were Mexican American (44\%). One hundred and sixty-four (164) mothers participated in this study; approximately half were Mexican American (45\%) and half were Euro-American (55\%; age $M=34.4$ ). One hundred and ten (110) fathers participated in this study (Mexican American: 56\%, EuroAmerican: 44\%; age $M=36.9$ ). These children and their families are participating in a longitudinal study examining the cultural and familial influences on childhood health socialization.

\section{Measures}

Mothers' and fathers' perceptions of the attractiveness and healthiness of females' body size and shape were assessed using a pictorial instrument with containing 12 line drawings that systematically manipulated 3 levels of weight (underweight, normal weight, and overweight, row 1, 2, and 3, respectively, in Fig. 1) and 4 levels of WHR (0.7, 0.8, 0.9, 1.0, column 1, 2, 3, and 4, respectively, in Fig. 1; Singh, 1993). All 12 drawings were randomly placed on a single page. Previous research with this pictorial measure has demonstrated that this measure is both salient and discriminating (Henss, 1995; Singh, 1993). An adapted, developmentally appropriate version of the WHR pictorial measure containing 6 stimuli figures was administered to early adolescent participants. ${ }^{8}$ This adapted

\footnotetext{
${ }^{8}$ The adults' version of this pictorial measure proved difficult for preadolescents to respond to. A pilot sample $(n=22)$ was then used to compute a test-retest reliability among children 9-12 years old for the measure used in the current study. Analyses revealed that participants selected the same body shape $55 \%$ of the time, and the same body size $77 \%$ of the time.
}

measure contained drawings that also manipulated 3 levels of weight and 4 levels of WHR, making it comparable to the adults' measure.

Participants' weight status and WHR were also measured. Participants' weight status was operationalized using Body Mass Index scores (BMI). Based on the recommendations of Lohman et al. (1988) 3 height and weight measurements were collected for each participant by trained research assistants and average weight and height were used to calculate BMI (weight $\mathrm{kg} / \mathrm{height} \mathrm{m}^{2}$ ). Additionally, 3 measures of participants' waist (at their smallest point) and hips (at their widest point) were taken, and their WHRs were calculated by dividing the average hip measurements by the average waist measurements.

\section{Procedure}

Preadolescents and their parents participating in this study completed questionnaires and other related measures in a 3 hour session in a laboratory setting. Preadolescents were interviewed by a trained research assistant, and parents could chose to read the questionnaires themselves or to have them read to them by research assistants. Participants chose to complete the assessments in either Spanish or English, and all measures administered in Spanish were translated and back-translated to assure their comparable meaning (Marín and Marín, 1991).

To complete the WHR pictorial measure, parents were asked to select the drawing they perceived as most attractive. They were then asked to repeat this procedure with a clean page containing all 12 line drawings by similarly indicating the drawing they found healthiest in appearance. Interviewers asked the preadolescents to indicate which single drawing of 6 was most attractive in appearance, and which single drawing was healthiest in appearance. During the laboratory visit, all participants' heights, weights, waist, and hip measurements were taken by trained research assistants. Upon completing all measures, families were assured that all their responses were confidential, and they were financially compensated for their time and effort.

\section{Analyses}

For all analyses, participants' perceptions of healthy and attractive body sizes (i.e. weight) and body shapes (i.e. WHR) were evaluated separately in order to investigate the relative explanatory value of social learning theory and evolutionary theory in accounting for these 2 different perceptions. Therefore, each participants' perception 
of a healthy and attractive female figure was coded to indicate which body size group (i.e., row of the pictorial measure) and which body shape group (i.e., column of the pictorial measure) they selected. Participants' perceptions of body size ranged from 1 to 3 , with 1 indicating the "underweight" category, 2 indicating the "normal" weight category, and 3 indicating the "overweight" category. Participants' perceptions of body shape ranged from 1 to 4 , with 1 indicating a WHR of $0.70,2$ indicating a WHR of $0.80,3$ indicating a WHR of 0.90 , and 4 indicating a WHR of 1.0. In all analyses, data was treated as categorical.

To assess family members' degree of agreement among their perceptions of healthy and attractive body sizes and shapes, Cohen's Kappa $(\kappa)$ was used. Although commonly used to examine interjudge agreement, $\kappa$ provides a means of assessing agreement (corrected for chance) among participants' perceptions of categorical stimuli.

To determine the relation between ethnic group membership and perceptions of healthy and attractive body sizes and shapes, separate chi squares $\left(\chi^{2}\right)$ were computed for mothers, fathers, and preadolescents. $\chi^{2}$ provides an omnibus assessment of similarity in selection between two groups, in this case Euro-American and Mexican American participants.

To determine mothers', fathers', and early adolescent preadolescents' preferences for healthy and attractive body sizes and shapes, $\chi^{2}$ were conducted. These $\chi^{2}$ took into account the different measures administered to parents and their children (with parents choosing from 12 stimuli pictures, and preadolescents choosing from 6 stimuli pictures; see Fig. 1) by adjusting the "expected" frequency values in accordance with the sample of pictures the participants' viewed. To assess the proportion contributed to the total $\chi^{2}$ by each cell, a percentage of the total $\chi^{2}$ value was computed using the equation: $\left((\text { observed }- \text { expected })^{2} /\right.$ expected $) / \chi^{2}$.

ANOVAs were used to determine if participants' selections of healthy and attractive body sizes and shapes were systematically related to their own body size (BMI) or shape (WHR). Participants' actual body size and shape were treated as continuous, dependent variables with the independent variable being the categorical selection (using the pictorial measurement) of healthy and attractive body sizes and shapes.

\section{RESULTS}

Kappa's were used to evaluate agreement among families members' perceptions of healthy and attractive body sizes and shapes. All of the kappas comparing mothers, fathers, and preadolescents (as well as preadolescents evaluated separately by gender) were very low indicating little agreement among family members' perceptions of healthy and attractive female bodies. Specifically, the average kappas for family members' perceptions of attractive and healthy weight figures were -0.02 (range $=$ -0.00 to -0.11 ) and 0.06 (range $=-0.06$ to 0.25 ), respectively. The average kappas for family members perceptions' of attractive and healthy WHRs were -0.01 (range $=0.01$ to 0.16$)$ and 0.03 (range $=0.00$ to 0.17 ), respectively.

To determine if there were differences between EuroAmerican and Mexican American mothers', fathers', and preadolescents' selections of healthy and attractive female body sizes and shapes, $\chi^{2}$ analyses were performed. None of the $12 \chi^{2}$ analyses conducted (attractive weight, attractive WHR, healthy weight, healthy WHR for mothers, fathers, and children) were significant. $\chi^{2}$ values for perceptions of body size $(d f=2)$ ranged from 0.57 to 3.93 with $p$ values of $>0.05 . \chi^{2}$ values for perceptions of body shape $(d f=3)$ ranged from 0.39 to 2.73 with $p$ values of $>0.05$.

Mothers', fathers', and preadolescents' perceptions of healthy and attractive female body sizes and shapes were determined utilizing the frequency with which each pictorial stimuli were selected (see Tables I and II). Both mothers and fathers tended to select "normal" weight women (row 2 in Fig. 1) as most healthy and attractive looking, while preadolescents were more inclined to select "thin" female figures (row 1 in Fig. 1) as most healthy and attractive in appearance relative to what would be expected. Mothers, fathers, and preadolescents all tended to select the pictorial stimuli with the smallest WHR (WHR of 0.70 ; column 1 in Fig. 1) as most attractive. However, participants' reports of the most healthy appearing body shape were less homogenous, with fathers in particular tending to select larger WHRs (WHR of 0.80; column 2 in Fig. 1) as healthy appearing more often than mothers and preadolescents did. Descriptive statistics are reported, and reveal parallel patterns of similarities and differences among participating mothers', fathers', and preadolescents' perceptions of healthy and attractive female body sizes and shapes (see Tables I and II).

ANOVAs reveal no significant relations between participants' actual WHR and their judgement of healthy and attractive WHRs for mothers $(F(3,129)=0.06, p=$ 0.98 , for healthy; $F(3,130)=0.03, p=0.99$, for attractive), fathers $(F(3,93)=0.11, p=0.96$, for healthy; $F(3,91)=0.08, p=0.97$, for attractive), and children 
Table I. Perceptions of Body Size (Weight)

\begin{tabular}{|c|c|c|c|c|c|}
\hline & \multirow[b]{2}{*}{ Mode } & \multicolumn{3}{|c|}{ Observed frequencies } & \multirow[b]{2}{*}{$\chi^{2}$} \\
\hline & & $R_{1}$ "Under" & $R_{2}$ "Normal" & $R_{3}$ "Over" & \\
\hline \multicolumn{6}{|l|}{ Attractive weight } \\
\hline Mother $(n=150)$ & 2 & $\begin{array}{r}63(50)^{a} \\
42 \%\end{array}$ & $\begin{array}{r}84(50) \\
56 \%\end{array}$ & $\begin{array}{c}3(50) \\
2 \%\end{array}$ & $70.68^{*}$ \\
\hline Father $(n=97)$ & 2 & $\begin{array}{c}31(32.33) \\
32 \%\end{array}$ & $\begin{array}{c}58(\mathbf{3 2 . 3 3}) \\
60 \%\end{array}$ & $\begin{array}{c}8(32.33) \\
8 \%\end{array}$ & $38.74^{*}$ \\
\hline Child $(n=155)$ & 1 & $\begin{array}{c}80(\mathbf{2 5 . 8 3}) \\
51 \%\end{array}$ & $\begin{array}{c}74(103.33) \\
48 \%\end{array}$ & $\begin{array}{c}1(25.83) \\
1 \%\end{array}$ & $145.8^{*}$ \\
\hline \multicolumn{6}{|l|}{ Healthy weight } \\
\hline Mother $(n=148)$ & 2 & $\begin{array}{c}47(49.33) \\
32 \%\end{array}$ & $\begin{array}{c}95(\mathbf{4 9 . 3 3 )}) \\
64 \%\end{array}$ & $\begin{array}{c}6(49.33) \\
4 \%\end{array}$ & $80.45^{*}$ \\
\hline Father $(n=99)$ & 2 & $\begin{array}{c}26(33) \\
26 \%\end{array}$ & $\begin{array}{r}65(33) \\
66 \%\end{array}$ & $\begin{array}{c}8(33) \\
8 \%\end{array}$ & $51.45^{*}$ \\
\hline Child $(n=156)$ & 2 & $\begin{array}{r}43(26) \\
28 \%\end{array}$ & $\begin{array}{c}103(104) \\
66 \%\end{array}$ & $\begin{array}{c}10(26) \\
6 \%\end{array}$ & $20.97^{*}$ \\
\hline
\end{tabular}

${ }^{a}$ Values in parentheses indicate expected frequencies.

Note. $R_{1}$ indicates figures in the 1 st row of the pictorial measure (Fig. 1) that were "underweight." $R_{2}$ indicates figures in the 2 nd row that were "normal" weight. $R_{3}$ indicates figures in the 3rd row that were "overweight." Values in bold indicate frequencies that are greater than expected and contribute the greatest amount to the overall $\chi^{2}$ value ( $\%$ of $\chi^{2}$ determined by $\left((\text { observed }- \text { expected })^{2} /\right.$ expected $\left.) / \chi^{2}\right)$.

$* p<0.05$.

$(F(3,150)=0.87, p=0.46$, for healthy; $F(3,149)=$ $0.47, p=0.70$, for attractive). Additionally, no significant relations were found between participants' actual weight status (BMI) and their judgements of healthy and attractive body sizes for mothers $(F(2,131)=0.23, p=$ 0.80 , for healthy; $F(2,132)=1.57, p=0.21$, for attractive), fathers $(F(2,95)=0.53, p=0.59$, for healthy; $F(2,93)=0.02, p=0.98$, for attractive $)$, and children

Table II. Perceptions of Body Shape (WHR)

\begin{tabular}{|c|c|c|c|c|c|c|}
\hline & \multirow[b]{2}{*}{ Mode } & \multicolumn{4}{|c|}{ Observed frequencies } & \multirow[b]{2}{*}{$\chi^{2}$} \\
\hline & & $C_{1}(0.70)$ & $C_{2}(0.80)$ & $C_{3}(0.90)$ & $C_{4}(1.0)$ & \\
\hline \multicolumn{7}{|l|}{ Attractive WHR } \\
\hline Mother $(n=150)$ & 1 & $\begin{array}{c}83(\mathbf{3 7 . 5})^{a} \\
55 \%\end{array}$ & $\begin{array}{c}53(37.5) \\
35 \%\end{array}$ & $\begin{array}{c}13(37.5) \\
9 \%\end{array}$ & $\begin{array}{c}1(37.5) \\
1 \%\end{array}$ & $113.15^{*}$ \\
\hline Father $(n=97)$ & 1 & $\begin{array}{c}45 \text { (24.25) } \\
47 \%\end{array}$ & $\begin{array}{c}41(24.25) \\
42 \%\end{array}$ & $\begin{array}{c}9(24.25) \\
9 \%\end{array}$ & $\begin{array}{c}2(24.25) \\
2 \%\end{array}$ & $59.33^{*}$ \\
\hline Child $(n=155)$ & 1 & $\begin{array}{c}115(77.5) \\
74 \%\end{array}$ & $\begin{array}{c}26(25.83) \\
17 \%\end{array}$ & $\begin{array}{c}10(25.83) \\
6 \%\end{array}$ & $\begin{array}{c}4(25.83) \\
3 \%\end{array}$ & $46.3^{*}$ \\
\hline \multicolumn{7}{|l|}{ Healthy WHR } \\
\hline Mother $(n=148)$ & 1 & $\begin{array}{r}71(37) \\
48 \%\end{array}$ & $\begin{array}{r}64(37) \\
43 \%\end{array}$ & $\begin{array}{c}10(37) \\
7 \%\end{array}$ & $\begin{array}{r}3(37) \\
2 \%\end{array}$ & $101.89^{*}$ \\
\hline Father $(n=99)$ & 2 & $\begin{array}{c}40(24.75) \\
40 \%\end{array}$ & $\begin{array}{c}43 \text { (24.75) } \\
44 \%\end{array}$ & $\begin{array}{c}15(24.75) \\
15 \%\end{array}$ & $\begin{array}{c}1(24.75) \\
1 \%\end{array}$ & $49.48^{*}$ \\
\hline Child $(n=156)$ & 1 & $\begin{array}{r}93 \text { (78) } \\
60 \%\end{array}$ & $\begin{array}{r}36(26) \\
23 \%\end{array}$ & $\begin{array}{r}22(26) \\
14 \%\end{array}$ & $\begin{array}{r}4(26) \\
3 \%\end{array}$ & $24.31^{*}$ \\
\hline
\end{tabular}

${ }^{a}$ Values in parentheses indicate expected frequencies.

Note. $C_{1}$ indicates figures in the first column of the pictorial measure (Fig. 1) that had a WHR of 0.70 . $C_{2}$ indicates figures in the second column that had a WHR of 0.80. $C_{3}$ indicates figures in the third column that had a WHR of $0.90 . C_{4}$ indicates figures that were in the fourth column that had a WHR of 1.0. Values indicate frequencies that are greater than expected and contribute the greatest amount to the overall $\chi^{2}$ value (\% of $\chi^{2}$ determined by: (observed - expected) $)^{2} /$ expected $=n / \chi^{2}$ ). ${ }^{*} p<0.05$. 
$(F(2,154)=0.57, p=0.57$, for healthy; $F(2,153)=$ $0.58, p=0.56$, for attractive) ${ }^{9}$

\section{DISCUSSION}

The aim of this study was to examine preadolescents' perceptions of healthy and attractive female body sizes and shape, and to investigate relations among preadolescents' perceptions and their parents' perceptions, as well as the association between ethnic group membership and participants' perceptions of females' body size and shape. These objectives were intended to not only determine preadolescents' perceptions of female body sizes and shapes, but to evaluate the utility of evolutionary theory and social learning theory in explaining preferences for female body sizes and shapes.

Overall, these findings do not suggest that preadolescents' perceptions of healthy and attractive female body sizes and shapes are influenced by the parents' preferences, or by their ethnic group membership. That is, the preadolescents participating in this sample do not appear to agree with their parents in their perceptions of healthy and attractive body sizes and shapes. The finding that "normal" size women were preferred by the adults in this study is contrary to other accounts that Euro-American adults prefer thin female figures (Feldman et al., 1988; Gordon, 2000; Powers and Erickson, 1986), but is similar to Singh's $(1993,1994 a)$ previous findings. Further, the finding of low agreement among family members' preferences is surprising in light of earlier reports of the importance of parents' influence on their children's perceptions of bodily attractiveness, body image, and related eating behaviors (Birch and Fisher, 1998; Davison et al., 2000; Pike and Rodin, 1991; Tinsley, 1992). As opposed to family members' maintaining similar preferences for female body sizes (i.e., as a function of social learning), these data suggest that familial influences may not be relevant to the development of preadolescents' body size ideals. The lack of family members' agreement in preferences for particular female figures' sizes demonstrated by these data may be a result of other societal influences outside of the family (e.g., media exposure) that may not be particularly sensitive to detection in a family-based research design and analysis strategy such as that employed in the present study. Thus, while this study did not investigate specific learning processes that might be conducive to intergenerational transmission of preferences for female body sizes and shapes, these data suggest that parents may play a

\footnotetext{
${ }^{9}$ Because of participants' tendency to prefer some body figures in the pictorial measure more than others, the ANOVAs were conducted with unequal $n \mathrm{~s}$, which may have led to insufficient power to find significance.
}

limited role in preadolescents' development of preferences for female body sizes and shapes. However, physical maturation during preadolescence and adolescence may influence youths' perceptions of females' body size and shape leading their preferences to become more like their parents' with age.

Previous studies have also detailed cultural patterns of preference suggesting that in the United States, Hispanic individuals select larger size female figures as more attractive than do Euro-American individuals (Winkelby et al., 1996). This finding was not duplicated in this study as similar preferences were reported by Euro-American and Mexican American participants, making it impossible to determine if unique socialization processes associated with ethnic group membership influence preadolescents' development of preferences concerning females' body sizes and shapes. However it should be noted that previous research aimed at understanding cultural influences on body size ideals and related eating behaviors among different ethnic groups have produced varying results (Crago et al., 1996; Lake et al., 2000; Striegel-Moore and Smolak, 2000). Thus, future research is needed to elucidate cultural processes potentially contributing to standards of bodily appearances.

Overall, these findings are consistent with evolutionary explanations offered for preferences concerning WHR, that assert both males and females, regardless of age and ethnic background, prefer female figures with small WHRs. Presumably, this preference arises because small WHRs are indicators of superior health status and reproductive capacity (Singh and Luis, 1995). However, contrary to principles proposed by evolutionary psychologists (e.g., Singh, 1993) that a unanimous preference for small WHRs exists, these results reveal that fathers differ in their judgments of the female WHRs they find most healthy, with preadolescents and mothers choosing smaller WHRs than do fathers as most healthy. In spite of the lack of unanimity in participants' preferences for female WHRs, the results from this study do not necessarily refute the evolutionary hypothesis presented by Singh (1993), since both adults and children did tend to select female figures with relatively small WHRs within what constitutes a normal, healthy range, and tended not to select figures with a WHR of 0.90 or 1.0 as healthy or attractive appearing. Furthermore, as preferences related to ethnicity did not emerge in participants' selections of pictures of figures with attractive WHRs, for the most part, these data support the early findings of Singh and others that report individuals' consistent preference for small WHRs (Singh, 1993; 1994a; Singh and Luis, 1995; Furnham et al., 1997).

These analyses also suggest that participants' own body dimensions (weight status and WHR) did not 
influence their selections of healthy and attractive female body sizes and shapes. Additional research focusing specifically on women's actual body dimensions and perceptions of bodily health and attractiveness may help us understand this finding.

\section{Limitations}

Although the results of this study represent an important first step in understanding preadolescents' perception of females' body shape, some limitations should be noted. The preadolescents' cognitive developmental status made it necessary to use an adapted version of the pictorial measure viewed by adults. While this measure did contain at least 1 picture from each of the 3 levels of weight group and the 4 levels of WHR, it did not contain all 12 pictures viewed by the parents. Future studies should continue to attempt administering the same measure to both parents and children to permit more identical comparisons by generation. Furthermore, although the line drawings used in this study have been proven valid stimuli for use in examining the construct of WHR (Singh, 1993), the quality of the line drawings may affect participants' interest in, and judgements of, the figures.

Because a relation between acculturative status and body image preferences has been documented (Joiner and Kashubeck, 1996), future studies should also seek to determine the relations between acculturation and perceptions of females' body size and shape. Further, because ethnicity and socioeconomic status (SES) are highly correlated, efforts to understand the influence of SES on perceptions of healthy and attractive figures should be made.

\section{Implications}

In spite of the aforementioned limitations, the findings from this study have several important implications. First, prior research aimed at understanding preadolescents' perceptions concerning body shape is unavailable. The current results suggest that body shape is a salient contributor to preadolescents' perceptions of female figures, and suggest that preadolescents' preferences for females' WHRs are similar to adults' preferences. Regardless of familial or ethnic influences, preadolescents tend to depict thin and curvaceous (i.e., "Barbie-doll-like") female figures as most attractive in appearance. This unrealistic ideal may subsequently affect youths', particularly females', feelings about their own developing bodies, and may have far-reaching consequences should they struggle to obtain this ideal (Attie and Brooks-Gunn, 1989). Since research suggests (Radke-Sharpe et al., 1990) that women's body ideals substantially contributes to their degree of body satisfaction and related eating behaviors (Furnham et al., 1990), the preference for thin, curvaceous female figures expressed by the preadolescents in this study may be detrimental to their developing body image, which in turn may impact their eating behaviors, and make them susceptible to maladaptive eating patterns.

In sum, the findings from this study have both theoretical and applied implications. Theoretically, these results contribute to our understanding of perceptions of bodily attractiveness and healthiness among preadolescents. Further, these findings have the potential to enhance our emerging models of the role of perceptions of females' body size and shape in preadolescents' identity development, specifically the development of body image. Within an applied perspective, these findings suggest that prevention and intervention strategies might better influence youths' perceptions of their bodies and the consequential quality of their dietary habits by considering the influence of perceptions of both body size and shape on preadolescents' development of body image ideals.

\section{ACKNOWLEDGMENTS}

This research was funded by a grant (\#HD32465-02) from the National Institute of Child Health and Development awarded to the second author. This paper is based on the masters thesis of the first author under the direction of the second author. An earlier version of this article was presented at the 1999 biennial meeting of the Society for Research in Child Development, Alberquerque, New Mexico. The authors thank the participating families and many research assistants who made this study possible. Furthermore, we are thankful to Jessica N. Gomel, Leann L. Birch, Mary Gauvain, Ross D. Parke, and Thomas L. Hansen for their helpful comments.

\section{REFERENCES}

Altabe, M., and Thompson, K. J. (1993). Body image changes during early adulthood. Int. J. Eating Disord. 13(3): 323-328.

Attie, I., and Brooks-Gunn, J. (1989). Development of eating problems in adolescent girls: A longitudinal study. Dev. Psychol. 25(1): 7079.

Attie, I., and Brooks-Gunn, J. (1995). The development of eating regulation across the life span. In Cicchetti, D., and Cohen, D. J. (eds.), Developmental Psychopathology: Vol. 2. Risk, Disorder, and Adaptation Wiley, New York, pp. 332-368.

Birch, L. L, and Fisher, J. O. (1998). Development of eating behaviors among children and adolescents. Pediatrics 101: 539-549. 
Bjorntorp, P. (1988). The associations between obesity, adipose tissue distribution and disease. Acta Medica Scand. (Supp.), 723: 121134.

Bjorntorp, P. (1991). Adipose tissue distribution and function. Int. J. Obesity 15: 67-81.

Brooks-Gunn, J., and Reiter, E. O. (1990). The role of pubertal processes. In Feldman, S. S., and Elliot, G. R. (eds.), At The Threshold: The Developing Adolescent. Harvard University Press, Cambridge, MA, pp. 16-53.

Brown, P. J., and Konner, M. (1987). An anthropological perspective on obesity. Ann. NY Acad. Sci. 499: 29-46.

Collins, E. M. (1991). Body figure perceptions and preferences among preadolescent children. Int. J. Eating Disord. 10(2): 199208.

Crago, M., Shisslak, C. M., and Estes, L. S. (1996). Eating disturbances among American minority groups: A review. Int. J. Eating Disord. 19(3): 239-248

Cramer, P., and Steimwert, T. (1998). Thin is good, fat is bad: How early does it begin? J. Appl. Develop. Psychol. 19(3): 429-451.

Davison, K. K., Markey, C. N., and Birch, L. L. (2000). Etiology of Body Dissatisfaction and Weight Concerns among 5-year-old Girls. Appetite 35: 143-151.

Dion, K. K. (1973). Young children's stereotyping of facial attractiveness. Dev. Psychol. 9(2): 183-188.

Ericksen, A. J., Tinsley, B. J., and Markey, C. N. (2000). Body Image and Weight Concerns Among Euro-American and Mexican American Preadolescent Girls. Unpublished Manuscript.

Feldman, W., Feldman, E., and Goodman, J. T. (1988). Culture versus biology: Children's attitudes toward thinness and fatness. Pediatrics 81: $190-194$

Field, A. E., Cheung, L., Wolf, A. M., Herzog, D. B., Gortmaker, S. L., and Colditz, G. A. (1999). Exposre to the mass media and weight concerns among girls. Pediatrics 103(3): E36.

Furnham, A., Hester, C., and Weir, C. (1990). Sex differences in the preferences for specific female body shapes. Sex Roles 22(11/12): $743-754$.

Furnham, A., Tan, T., and McManus, C. (1997). Waist-to-hip ratio and preferences for body shape: A replication and extension. Pers. Indiv. Differ. 22(4): 539-549.

Goldfield, A. and Chrisler, J. C. (1995). Body stereotyping and stigmatization of obese persons by first graders. Percept. Mot. Skills 81: 909-910.

Gordon, R. A. (2000). Eating Disorders: Anatomy of a Social Epidemic (2nd edn.). Blackwell Publishers, Malden, MA.

Harter, S. (1990). Developmental differences in the nature of selfrepresentations: Implications for the understanding, assessment and treatment of maladaptive behavior. Cogn. Ther. Res. 14: 113142

Harter, S. (1998). The development of self-representations. In Damon, W., and Eisenberg, N. (Eds.) Handbook of Child Psychology (5th edn., Vol. 3) Wiley, New York, pp. 553-617.

Henss, R. (1995). Waist-to-hip ratio and attractiveness: Replication and extension. Pers. Indiv. Differ. 19(4): 479-488.

Jackson, L. A., and McGill, O. D. (1996). Body typed preferences and body characteristics associated with attractive and unattractive bodies by African Americans and Anglo Americans. Sex Roles 35(5/6): 295-307.

Joiner, G. W., and Kashubeck, S. (1996). Acculturation, body image, self-esteem, and eating-disorder symptomatology in adolescent Mexican American women. Psychol. Women Q. 20: 419435.

Jones, P. R. M., Hunt, M. J., Brown, T. P., and Norgan, N. G. (1986). Waist-hip circumference ratio and its relation to age and overweight in British men. Human Nutr. Clin. Nutr. 40C: 239247.

Klesges, R. C., Malott, J. M., Boschee, P. F., and Weber, J. M. (1986). The effects of parental influences on children's food intake, physical activity, and relative weight. Int. J. Eating Disord. 5(2): 335-346.
Lake, A. J., Staiger, P. K., and Glosinski, H. (2000). Effect of Western culture on women's attitudes to eating and perceptions of body shape. Int. J. Eating Disord. 27(1): 83-89.

Langlois, J. H., and Roggman, L. A. (1990). Attractive faces are only average. Psychol. Sci. 1: 115-121.

Langlois, J. H., Roggman, L. A., and Musselman, L. (1994). What is average and what is not average about attractive faces? Psychol. Sci. 5: 214-220.

Lerner, R. M., and Gellert, E. (1969). Body build identification, preference, and aversion in children. Dev. Psychol. 1(5): 456-462.

Lohman, T. G., Roche, A. F., and Martorell, M. (1988). Anthropometric Standardization Reference Manual. Human Kinetics, Champaign, IL.

Maloney, M. J., McGuire, J., Daniels, S. R., and Specker, B. (1989). Dieting behavior and eating attitudes in children. Pediatrics 84: 482-489.

Marín, G., and Marín, B. V. (1991). Research with Hispanic Populations. Sage, Newbury Park.

Martin, J. E. (1989). The role of body image in the development of bulimia. Brit. J. Occup. Ther. 52(7): 262-265.

Pike, K. M., and Rodin, J. (1991). Mothers, daughters, and disordered eating. J. Abnorm. Psychol. 100(2): 198-204.

Pliner, P., Chaiken, S., and Flett, G. L. (1990). Gender differences in concern with body weight and physical appearance over the life span. Pers. Soc. Psychol. Bull. 16(2): 263-273.

Powers, P. S. (1980). Obesity: The regulation of weight. Williams and Wilkins, Baltimore.

Powers, P. D., and Erickson, M. T. (1986). Body-image in women and its relationship to self-image and body satisfaction. J. Obesity and Weight Regul. 5(1): 37-50.

Radke-Sharpe, N., Whitney-Saltiel, D., and Rodin, J. (1990). Fat distribution as a risk factor for weight and eating concerns. Int. J. Eating Disord. 9(1): 27-36.

Rolland, K., Farnhill, D., and Griffiths, R. A. (1996). Children's perceptions of their current and ideal body sizes and body mass index. Percep. Mot. Skills 82: 651-656.

Rolland, K., Farnhill, D., and Griffiths, R. A. (1997). Body figure perceptions and eating attitudes among Australian schoolchildren aged 8 to 12 years. Int. J. Eating Disord. 21: 273-278.

Rosenblum, G. D., and Lewis, M. (1999). The relations among body image, physical attractiveness, and body mass index in adolescence. Child Dev. 70(1): 50-64

Rudofsky, B. (1972). The Unfashionable Human Body. Doubleday, New York.

Singh, D. (1993). Adaptive significance of female physical attractiveness: Role of waist-to hip ratio. J. Pers. Soc. Psychol. 65(2): 293307

Singh, D. (1994a). Body fat distribution and perception of desirable female body shape by young black men and women. Int. J. Eating Disord. 16(3): 289-294.

Singh, D. (1994b). Ideal female body shape: Role of body weight and waist-to-hip ratio. Int. J. Eating Disord. 16(3): 283-288.

Singh, D. (1994c). Is thin really beautiful and good? Relationship between waist-to-hip ratio (WHR) and female attractiveness. Pers. Indiv. Differ. 16(1): 123-132.

Singh, D., and Luis, S. (1995). Ethnic and gender consensus for the effect of waist-to-hip ratio on judgement of women's attractiveness. Hum. Nat. 6(1): 51-65.

Slap, G. B., Khalid, N., Paikoff, R. L., Brooks-Gunn, J. (1994). Evolving self-image, pubertal manifestations, and pubertal hormones: Preliminary findings in young adolescent girls. J. Adolesc. Health 15(4): 327-335.

Stice, E. (1998). Modeling of eating pathology and social reinforcement of the thin-ideal predict onset of bulimic symptoms. Behav. Res. Ther. 36(10): 931-944.

Striegel-Moore, R. H., and Smolak, L. (2000). The influence of ethnicity on eating disorders in women. In Eisler, R. M., and Hersen, M. (eds.) Handbook of Gender, Culture, and Health. Lawrence, Mahwah, NJ, pp. 227-253. 
Thompson, S. H., Corwin, S. J., and Sargent, R. G. (1997). Ideal body size beliefs and weight concerns of fourth grade children. Int. J. Eating Disord. 21(3): 279-284.

Tinsley, B. J. (1992). Multiple influeces on the acquisition and socialization of children's health attitudes and behavior: An integrative review. Child Dev. 63(5): 1043-1069.
Winkleby, M. A., Gardener, C. D., and Taylor, C. B. (1996). The influence of gender and socioeconomic factors on Hispanic/White differences in body mass index. Prev. Med. 25: 203-211.

Wiseman, L. V., Gray, J. J., Mosimann, J. E., and Ahrens, A. H. (1992). Cultural expectations of thinness in women: An update. Int. J. Eating Disord. 11(1): 85-89. 